\title{
RESISTÊNCIA À SECA EM QUATRO CULTIVARES DE TRIGO: PARÂMETROS FISIOLÓGICOS ${ }^{1}$
}

\author{
I.A.M. DENADAr; A.E. KLAR ${ }^{3}$ \\ ${ }^{2}$ Estagiána do Departamento de Engenharia Rural-FCA/UNESP \\ ${ }^{3}$ Depto. de Engenharia Rural-FCAUNESP, C.P. 237, CEP: 18600-970 - Botucatu, SP.
}

\begin{abstract}
RESUMO: A resistência à seca foi estudada em quatro cultivares de trigo, dois de porte baixo: Anahuac e LAC-24 e dois de porte alto, BH-1146 e IAC-23, em dols tratamentos de irrigaçã I-vasos constantemente molhados por capilaridade; II- vasos irrigados quando o potencial de água do solo atingisse, aproximadamente, $-1,5 \mathrm{MPa}$. $\mathrm{O}$ potencial de água e o teor relativo de água das folhas foram mais elevados no tratamento precondicionado ao estresse, em relaçá ao irrigado por capilaridade, em todos os cultivares sob as mesmas condiçóes de umidade do solo em ambos os estádios considerados: desenvolvimento vegetativo e reprodutivo. Embora os estômatos das plantas do tratamento submetido ao estresse permanecessem abertos a potenciais de água mais negativos que naqueles em que as plantas recebiam água constantemente, nåo fol possivel separar genótipos mais ou menos resistentes à seca, utilizando-se a difusividade ao vapor d'água dos estômatos acoplada ao teor relativo de água e ao potencial de dgua das folhas.

Descritores: potencial de água, difusividade das folhas ao vapor d'água, teor relativo de água das folhas
\end{abstract}

\section{DROUGHT RESISTANCE IN WHEAT CULTIVARS: PHYSIOLOGICAL PARAMETERS}

\begin{abstract}
The drought resistance was studied for four wheat cultivars: two dwarfs: Anahuac and IAC-24 and two tall ones: BH-1146 and IAC-23, using a treatment I constantly wetted by capilarity, and other one, II, which received water when soil water potential reached $-1,5 \mathrm{MPa}$. Leaf water potential and relative water content were higher in treatment 11 than in treatment $I$, at the same soll water potentials for all cultivars, in the two development stages (vegetative, and reprodutive). There was no way of separating genotypes more or less resistant to drought, only using the relations between leaf water potential and leaf diffusive resistance to water vapour.

Key Words: drought resistance; leaf water potencial; leaf diffusive, leaf resistance to water vapour
\end{abstract}

\section{INTRODUÇÃO}

A perda de água do tecido da planta produz efeitos diretos: a) redução do potencial químico ou atividade da água; b) concentração de macromoléculas e de solutos de baixos pesos moleculares; c) alterações nas relações espaciais em membranas e nas organelas através da redução do volume; d) redução na pressão hidrostática dentro das células, além de outros.

A água de irrigação é um dos recursos cada vez mais limitante no universo, dai a necessidade de técnicas que permitam aumentar a produtividade das culturas a cada unidade de volume de água aplicada.

A produtividade do trigo depende da quantidade de água disponivel no solo. Os cultivares tolerantes à seca podem reduzir a quantidade de água consumida, e/ou produzirem mais grăos para uma mesma quantidade de água (SAYED, 1983).

$O$ desenvolvimento de cultivares tolerantes à seca tem sido um dos objetivos primordiais nos programas de melhoramento genético em trigo (BRUCKENER E FROHBERG, 1987), e requer a identificação de mecanismos físiológicos importantes para serem usados como critério de seleção (BLUM et al., 1981).

Métodos de seleção para caracteres quantitativos foram sugeridos por GRAFIUS et al. (1965), mas foram pouco usados para seleção em resistência à seca, provavelmente devido ao pouco conhecimento do mecanismo das respostas das plantas aos déficit hidricos.

Os mecanismos de resistência à seca podem ser de três tipos: "evitar", "tolerar" e "escapar" à seca como foi descrito por LEVTT (1972). "Evitar" à seca ocorre quando o "status" de água é mantido em potenciais elevados, mesmo em presença de ambientes secos. As plantas evitam a seca através do fechamento dos estômatos, aprofundando as raizes para extração de água, diminuindo o tamanho das células, espessando as paredes celulares, aumentando a cerosidade da cutícula etc., para a manutenção de suas funções físiológicas; "tolerar" à seca acontece quando as funções das plantas são mantidas em equilibrio durante um déficit hídrico interno elevado, com baixos potenciais de água; e "escapar" à

\footnotetext{
' Aprovado no XXII Congresso Brasileiro de Engenharia Agrícola - Illéus, BA. 1993.
}

Sci. agric., Piracicaba, 52(2):274-281, mai./ago. 1995 
seca ocorre quando a planta completa seu ciclo antes do advento da seca, ou seja, o seu ciclo ocorre nos períodos hídricos favoráveis do ano.

Existe uma falta de integração da pesquisa básica, estudos de respostas totais da planta e testes de campo, especialmente para relacionar a integração dos fatores ambientais.

HAND et al. (1982), estudando respostas fisiológicas para resistência à seca em plântulas de pera, verificaram significativa correlação entre resistência difusiva dos estômatos ao vapor d'água e potencial de água da folha.

THOMAS et al. (1976) observaram que em plantas de sorgo e algodăo quando precondicionadas à seca através de ciclos curtos e freqüentes, os estômatos permaneceram abertos a menores potenciais de água da folha que as plantas não precondicionadas. Os autores relataram o mesmo resultado para trabalhos realizados em câmara de vegetação e em condições de campo.

EHRLER E NAKAYAMA (1984) verificaram que os valores de teor relativo de água da folha (TRA) podem ser utilizados para definir o "status" de água da planta e planejar a irrigação em Parthenium argentatum, GRAY (borracha natural).

Em trigo, os valores do teor relativo de água das folhas foram relativamente elevados no periodo vegetativo; após o florescimento, diminuem progressivamente até o início da senescência (Fischer et al., 1966, citado por RODRIGUES et al., 1980).

$O$ déficit hidrico no estádio de florescimento em trigo refletiu em uma menor produçăo quando comparada ao mesmo déficit aplicado em qualquer outro estádio de desenvolvimento. As variaçőes intergenotípicas em evitar a seca neste estádio mostraram ser importantes (BLUM et al., 1981).

O presente trabalho teve como objetivo principal avaliar a influência do déficit de água sobre os parâmetros: potencial de água, teor relativo de água e difusividade ao vapor d'água das folhas em quatro cultivares de trigo, dois de porte baixo e outros dois de porte alto, visando sua utilização na seleçăo de cultivares tolerantes ou não à seca.

\section{MATERIAL E METODOS}

O experimento foi conduzido em casa de vegetação situada no Departamento de Engenharia Rural da Faculdade de Ciências Agronômicas UNESP, Câmpus de Botucatu, 800 metros de altitude. $O$ solo utilizado corresponde ao grande grupo Terra Roxa Estruturada, designado Unidade Lageado com algumas características físicas constantes na TABELA 1 e químicas na TABELA 2.

TABELA 1 - Análise textural e densidade aparente (Da) do solo.

\begin{tabular}{cccc}
\hline ARGLA & LIMO & AREIA & Da \\
\hline$(\%)$ & $(\%)$ & $(\%)$ & $\left(\mathrm{g} / \mathrm{cm}^{3}\right)$ \\
\hline 56,0 & 15,0 & 29,0 & 1,0 \\
\hline
\end{tabular}

TABELA 2 - Características químicas do solo.

\begin{tabular}{|c|c|c|c|c|c|c|c|c|c|}
\hline \multirow[b]{2}{*}{$\begin{array}{c}\mathrm{pH} \\
\left(\mathrm{em} \mathrm{H_{2 }} \mathrm{O}\right)\end{array}$} & \multirow[b]{2}{*}{$\begin{array}{l}\text { M.O. } \\
(\%)\end{array}$} & \multirow[b]{2}{*}{$\begin{array}{l}\mathrm{P}(\text { resina }) \\
\left(\mu \mathrm{g} / \mathrm{cm}^{3)}\right.\end{array}$} & \multicolumn{7}{|c|}{ mili equiv. $/ 100 \mathrm{~cm}^{3} \mathrm{~T}$ FSA } \\
\hline & & & $\mathrm{H}+\mathrm{AL}$ & $\mathbf{K}$ & $\mathrm{Ca}$ & $\mathbf{M g}$ & $\mathbf{S}$ & CTC & $\begin{array}{l}\mathrm{V} \\
\%\end{array}$ \\
\hline 5,4 & 1,0 & 11,0 & 4,2 & 0,41 & 0,59 & 1,30 & 3,7 & 4,35 & 47,00 \\
\hline
\end{tabular}

A calagem foi realizada 30 dias antes da semeadura, utilizando-se $4,0 \mathrm{~g}$ de $\mathrm{CaCO}_{3}$ por vaso. Cada vaso recebeu $150 \mathrm{ppm}$ de $P$ na forma de superfosfato simples $\left(20 \% \mathrm{P}_{2} \mathrm{O}_{\mathrm{s}}\right), 80 \mathrm{ppm}$ de $\mathrm{K}$ na forma de cloreto de potássio $\left(60 \% \mathrm{~K}_{2} 0\right)$ e $40 \mathrm{ppm}$ de N na forma de sulfato de amônia $(20 \% \mathrm{~N})$ no plantio e, a cada 30 dias mais, 10 ppm de $N$ até 0 florescimento. A curva característica de umidade do solo foi obtida através de placas de pressão, com os valores de potencial matricial de $-0,01 ;-0,03$; 0,$05 ;-0,08 ;-0,5$ e $-1,5 \mathrm{MPa}$, correspondentes a 29,5 ; 25,$3 ; 23,5 ; 22,6 ; 19,7$ e $19,0 \%$ de umidade do solo com base em peso de solo seco. Foi instalado um temohigrógrafo dentro da casa de vegetação para representar as condiçőes microclimáticas do ambiente. No período de mediçóes de um ciclo de seca no estádio vegetativo (29/6 a $10 / 7)$, a temperatura média diária foi $17,5 \pm 2,5^{\circ} \mathrm{C}$ e a umidade relativa 
média diária, $71,5 \pm 9 \%$. No estádio reprodutivo ( 7 a $17 / 8$ ), a temperatura média diária foi $20,9 \pm 77^{\circ} \mathrm{C}$ e a umidade relativa diária média, $54,3 \pm 10 \%$.

Foram usados quatro cultivares de trigo (Triticum aestivum, L.): Anahuac, susceptivel ao alumínio do solo, porte baixo, ciclo de $120 \pm 5$ dias; IAC24 , tolerante ao alumínio, porte baixo e ciclo de 120 \pm 5 dias; IAC-23, susceptível ao alumínio, porte alto, ciclo de $110 \pm 5$ dias; BH-1146, tolerante ao alumínio, porte alto, ciclo de $110 \pm 5$ dias. Todos são recomendados para o plantio no Estado de São Paulo (FELíCIO et al., 1986).

Foram semeadas quinze sementes por vaso à profundidade de $1,0 \mathrm{~cm}$ em 26/05/87, irrigando-se com $500 \mathrm{ml}$ de água para que ocorresse a germinação. Fez-se o desbaste, deixando-se dez plantas por vaso, quando procederam-se às irrigações, conforme delineado nos tratamentos. Foram utilizados vasos de plástico com $25 \mathrm{~cm}$ de diâmetro, $40 \mathrm{~cm}$ de altura, contendo $8.000 \mathrm{~g}$ de terra seca em estufa, peneirada em malha $5 \mathrm{~mm}$. Os vasos usados no tratamento irrigado foram furados na base e no lado interno colocou-se tela.

Adotaram-se dois tratamentos: I - Irrigado - os vasos foram mantidos constantemente irrigados por capilaridade recebendo água de uma camada de areia úmida com $10 \mathrm{~cm}$ de espessura dentro de uma bandeja de folha de flandres; II - Seco - procedia-se à irrigação toda vez que o potencial matricial do solo atingisse as imediações de $-1,5 \mathrm{MPa}$ As determinações fisiológicas foram realizadas em dois vasos de cada parcela no periodo vegetativo. No dia anterior ao início das leituras, os vasos do tratamento seco foram irrigados para que o potencial de água do solo atingisse valores próximos à $-0,01 \mathrm{MPa}$, semelhante ao potencial de água do solo dos vasos do tratamento irrigado. As leituras foram feitas no horário das 11:00 às 13:00 horas, diariamente, até que o potencial de água do solo chegasse à $-1,5 \mathrm{MPa}$, aproximadamente. Após o florescimento (periodo reprodutivo), repetiram-se as mesmas medições usando-se a mesma conduta adotada para o estádio vegetativo, com excessão da porometria, pois houve quebra do aparelho medidor.

Para determinar a resistência difusiva ao vapor d'água $\left(r_{s}\right)$, utilizou-se de um porômetro automático, com as leituras sendo feitas na folha mais nova completamente desenvolvida, na superficie abaxial. As medidas foram realizadas uma vez ao dia durante um ciclo de seca do período vegetativo. Imediatamente após a leitura da resistência difusiva ao vapor d'água, proceda-se à leitura do potencial de água da folha utilizando-se de câmara de pressão e do teor relativo de água das folhas conforme técnicas expressas por KLAR (1988).

Utilizou-se o delineamento experimental inteiramente casualizado com quatro repetições, perfazendo-se um total de 32 vasos. Análise estatistica limitou-se à regressão e correlação dos fatores estudados.

\section{RESULTADOS E DISCUSSĀO}

Na Figura 1 está representada a resistência difusiva dos estômatos ao vapor d'água durante o período das determinações, no estádio vegetativo, mostrando que os estômatos das plantas do cultivar Anahuac (porte baixo) permaneceram abertos durante cerca de seis dias nas plantas irrigadas constantemente; nas precondicionadas à seca, somente após dez dias de secamento a $r_{s}$ aumentou causando o fechamento dos estômatos.

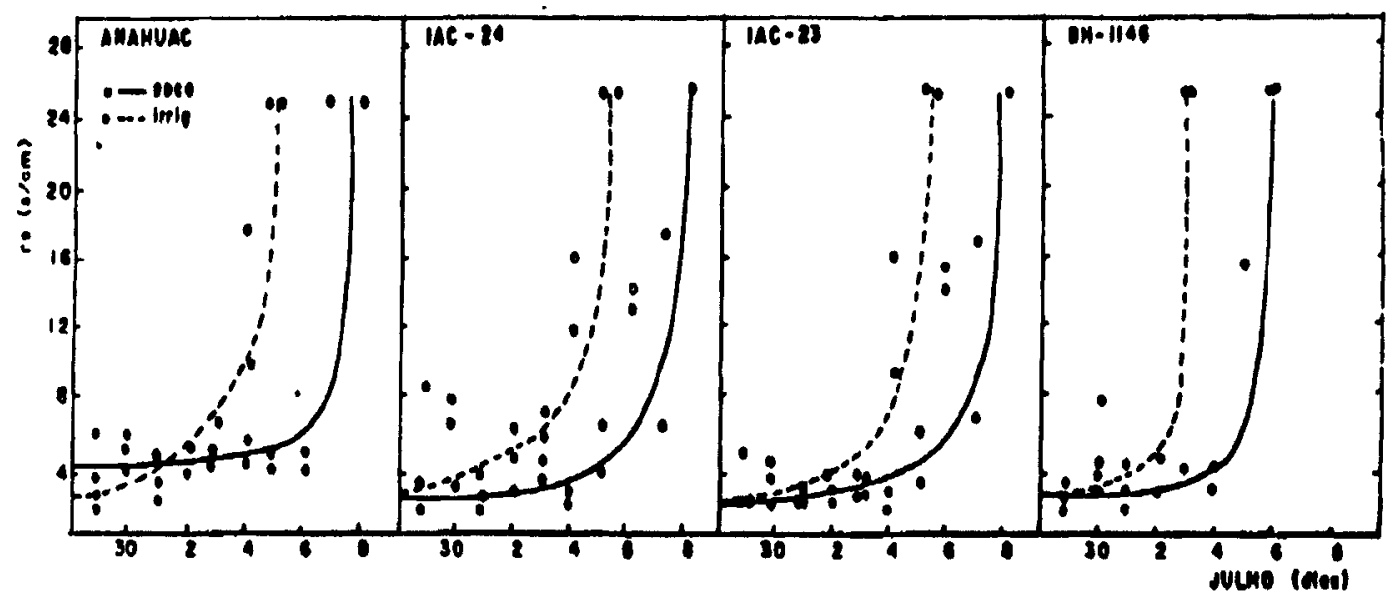

Figura 1 - Resistência difusiva dos estômatos ao vapor d'agua $\mathrm{x}$ tempo estádio vegetativo 
De acordo com KLAR et al. (1985), em plantas de trigo precondicionadas à seca, a resistência difusiva dos estômatos ao vapor d'água aumenta nas horas mais quentes do dia mesmo em solo com condições de umidade favoráveis. As plantas quando submetidas a ciclos de seca têm seu desenvolvimento vegetativo diminuido, as paredes celulares a a cuticula das folhas espessadas, aumento da relação raiz/parte aérea, mudança na coloração das folhas, além de afetar outros fatores. Tais alterações mantêm mais elevados os seus potenciais de água, sob os mesmos potenciais de água do solo quando comparados aos das plantas constantemente irrigadas, o que LEVITT (1972) convencionou denominar "evitar a seca".

Os cultivares IAC-24 (porte baixo) e IAC-23 (porte alto) tiveram comportamentos semelhantes ao cultivar Anahuac (porte baixo) quanto ao tempo para o fechamento dos estômatos. Por outro lado, a elevação de $r_{s}$ ocnrreu mais cedo no $\mathrm{BH}-1146$ (porte alto) que nos outros cultivares tanto no tratamento irrigado como no seco, com os estômatos se fechando no quinto e oitavo dias, respectivamente. Logo, este cultivar se ressente sob déficits hidricos mais rapidaniente devido, provavelmente, à sua maior massa verde em relação aos outros, o que deverá dimınuir seu crescimento sob seca, pois é este mecanısmo de decréscimo na saída de água que faz com que haja menor entrada de $\mathrm{CO}_{2}$ nas folhas, consequentemente produzindo menos fotossintetizados.

Entre os cultivares de porte baixo, no estádio vegetativo, o Anahuac manteve potenciais de água das folhas inferiores ao cultivar IAC-24 no tratamento irrigado, conforme mostra a Figura 2, durante um ciclo de seca.

As plantas do cultivar Anahuac, quando não precondicionadas à seca, desenvolvem maior tensão para absorção da água que o IAC-24. Após nove dias de secamento, a diferença entre o tratamento irrigado e o precondicionado à seca, para o cultivar Anahuac foi $-0,89 \mathrm{MPa}$, enquanto que para o IAC24 foi de $-0,34 \mathrm{MPa}$. Surge então uma questão: em termos de sobrevivência à falta d'água, as plantas, cujos potenciais de água caem drasticamente como no Anahuac sob seca, teriam maiores possibilidades de sobrevivência que outras, como o IAC-24? Parece que sim, pois, o Anahuac tem maior queda também na produtividade que seria sacrificada sm função da própria sobrevivência. É uma ques iăo que poderá ser respondida com outros ensaios que envolveriam tratamentos com o intuito de avaliar o potencial minimo de água na planta.

Em trabalho desenvolvido por KLAR et al. (1988), o cultivar Anahuac mostrou-se mais produtivo nos tratamentos irrigados dentre nove cultivares estudados. No entanto, quando submetido à seca foi o menos produtivo. Houve uma queda palpável desta variável na tentativa das plantas se adaptarem às condições de estresse hidrico. Logo, os critérios potencial de água da folha $\mathrm{x}$ tempo e produtividade tiveram comportamentos parecidos.

De acordo com BLUM et al. (1981), os genótipos condicionados à seca que mantém potenciais de água da folha mais elevados durante períodos de seca às mesmas condições ambientais, podem ser considerados mais resistentes à falta de água. $\mathrm{Na}$ fase vegetativa dos cultivares de porte alto, as diferenças entre os tratamentos irrigado e seco, em nove dias após a suspensão da irrigação, foram de 0,86 e $-0,32 \mathrm{MPa}$ para os cultivares IAC-23 e BH1146, respectivamente. Portanto, pode-se conduzir o mesmo raciocínio que se fez com relação aos cultivares de porte baixo.

No tratamento seco, os potenciais de água das folhas foram praticamente semelhantes para todos os cultivares

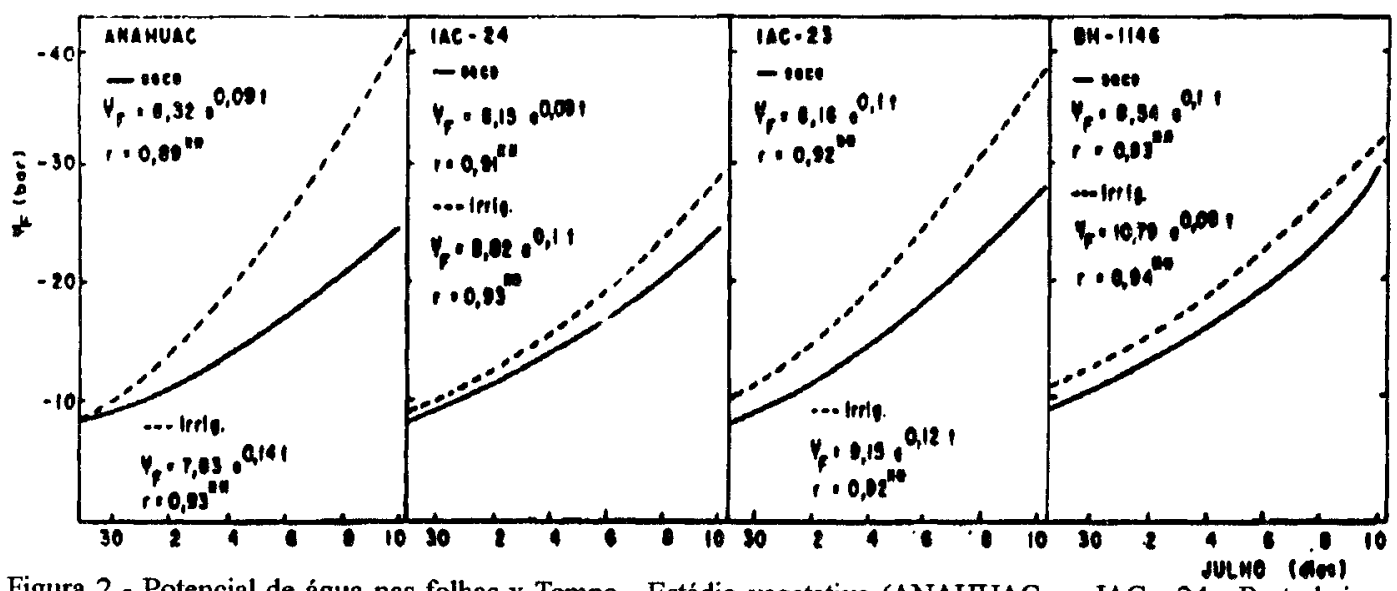

Figura 2 - Potencial de água nas folhas x Tempo - Estádio vegetativo (ANAHUAC e IAC - 24 - Porte baixo, e BH -1146 Porte alto) * $\mathrm{e}^{* *}$ - Significativos a 5 e A $1 \%$, respectivamente

Sci. agric., Piracicaba, 52(2):274-281, mai./ago. 1995 
Os genótipos de porte baixo no estádio reprodutivo (Figura 3 ) apresentam comportamentos semelhantes na curva de $a_{f} \times$ tempo, quando comparados ao estádio vegetativo, aos nove dias do início da fase de interrupção da irrigação. O cultivar Anahuac mostrou uma diferença de 1,49 $\mathrm{MPa}$ entre o tratamento constantemente irrigado e o tratamento seco, enquanto que o IAC-24 apresentou uma diferença de apenas $0,32 \mathrm{MPa}$.

As diferenças apresentadas pelos cultivares IAC-23 e BH-1146 (porte alto), utilizando-se do mesmo critério, corresponderam a 0,232 e $2,0 \mathrm{MPa}$ e a ordem crescente de adaptação à seca, usando-se deste critério, foi a mesma para os estádios vegetativo e reprodutivo, e consiste na seguinte: IAC-23, IAC24, Anahuac, BH-1146. Há que se considerar para o estádio reprodutivo o maior número de ciclos de seca envolvidos e por ser este o periodo em que as plantas mais se recentem de déficits hídricos.

$\mathrm{Na}$ Figura 4 são apresentados os valores de condutância versus potencial de água das folhas, dos tratamentos e cultivares. Observa-se que o fechamento dos estômatos, segundo metodologia de KLAR et al. (1978), deu-se em $\bullet_{\mathrm{f}}$ de $-2,4$ a $-2,6 \mathrm{MPa}$
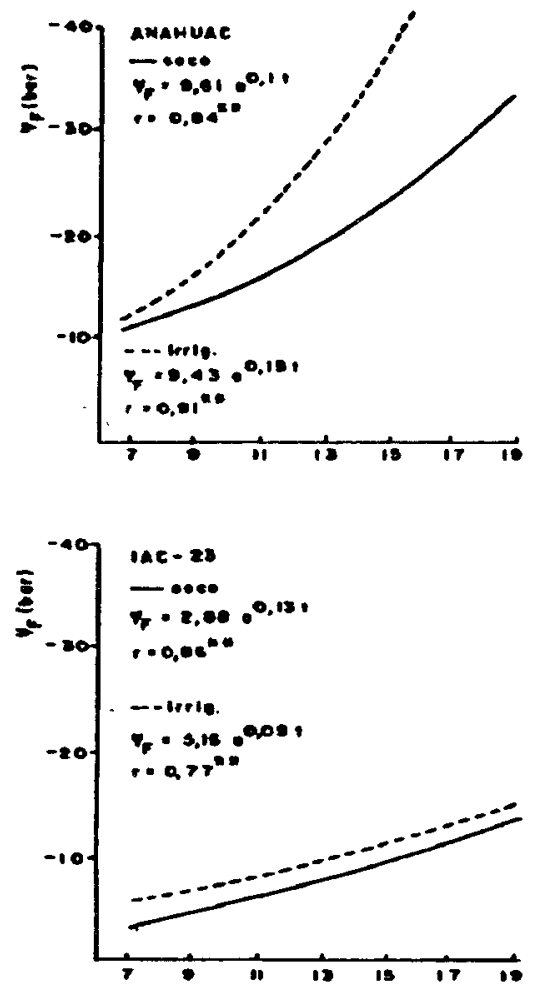

no tratamento seco e $-2,1$ a $-2,3 \mathrm{MPa}$ no tratamento constantemente irrigado para os quatro cultivares, mostrando que as diferenças em $b_{\mathrm{f}}$ que ocorreram entre os cultivares para o fechamento dos estômatos, talvez não sejam suficientemente significativas para separar os genótipos no que tange à resistência à seca. Entretanto, as plantas submetidas ao tratamento seco mostraram ter capacidade de adaptarem-se a déficits hidricos, mantendo os estômatos abertos a menores potenciais de água das plantas. Conforme mostram as Figuras 5 e 6, os TRA dos quatro cultivares, quando precondicionados à seca, mantiveram-se mais elevados que as plantas do tratamento constantemente irrigado, indicando que houve adaptação das plantas às condições de déficit hídrico.

No estádio vegetativo (Figura 5), as diferenças de TRA entre o tratamento irrigado e o tratamento seco, aos nove dias de secamento, dos cultivares de porte baixo foram $22,6 \%$ para o Anahuac e 18,9\% para o IAC-24 e foram menores que as diferenças dos cultivares de porte alto, (IAC-23, 31,7\% e BH$1146,29,6 \%$ ). Para o tratamento irrigado constantemente, os TRA dos cultivares de porte alto, foram menores (em torno de 13\%) que dos cultivares de
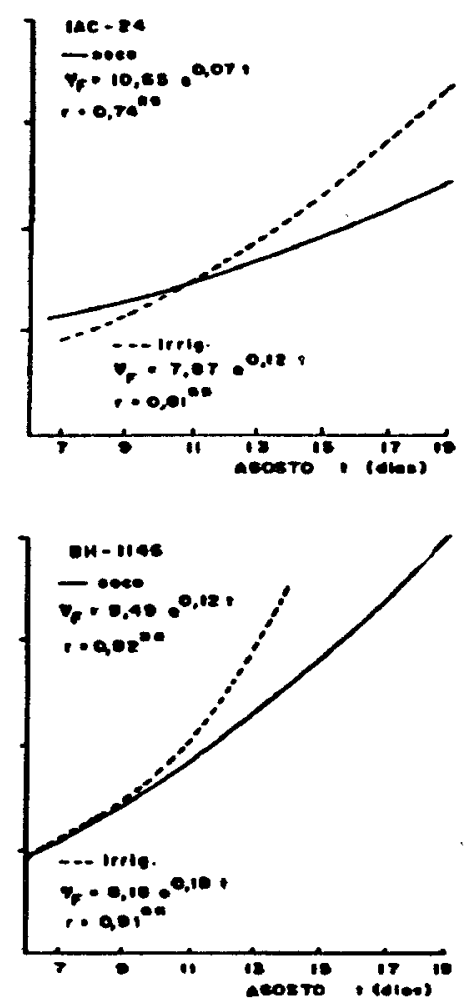

Figura 3 - Potencial de água nas folhas x Tempo - Estádio reprodutivo (ANAHUAC e IAC - 24 - Porte baixo; IAC - 23 e BH - 1146 - Porte alto).

Sci. agric., Piracicaba, 52(2):274-281, mai./ago. 1995 

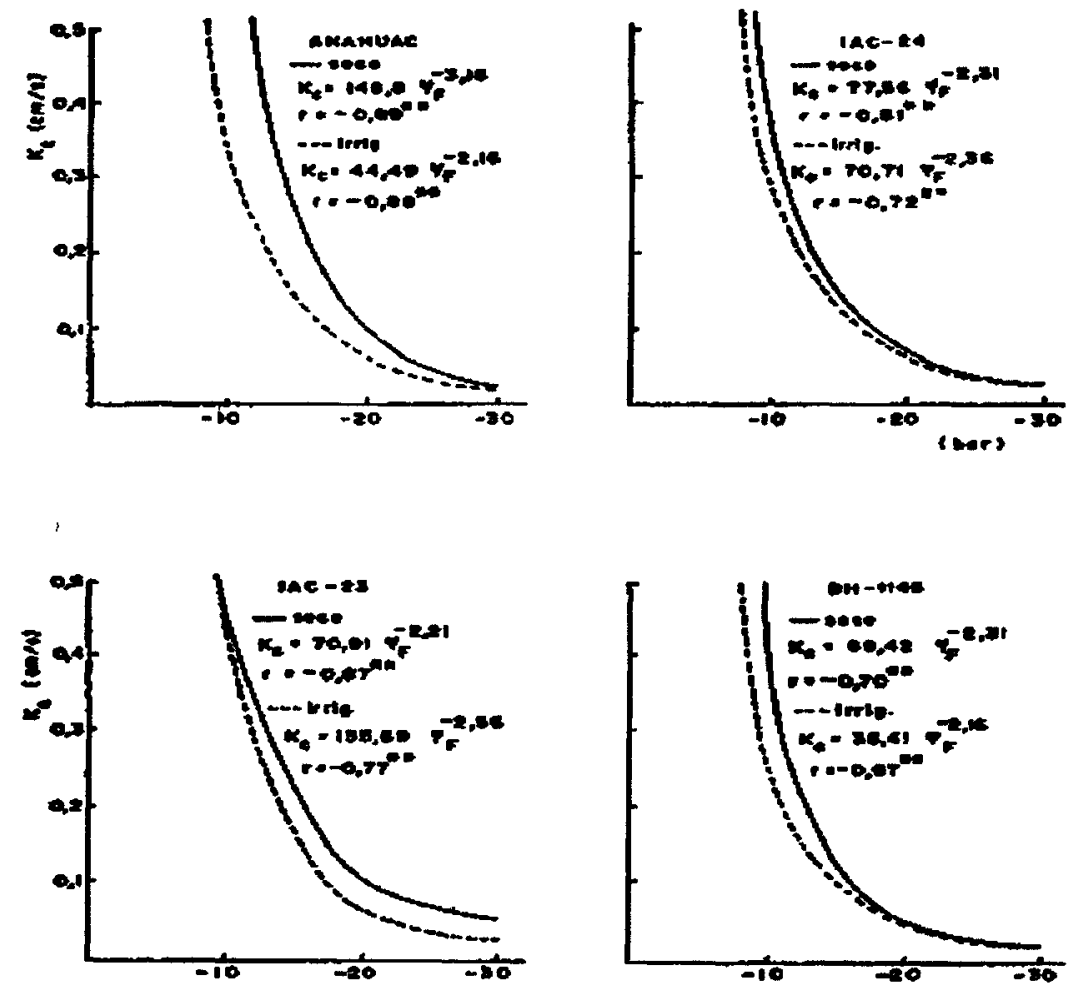

Figura 4 - Condutância estomática $x$ Potencial de água nas folhas no Estágio vegetativo - (ANAHUAC e IAC - 24 - Porte baixo; IAC - 23 e BH -1146 - Porte alto).

porte baixo no mesmo $9^{\circ}$ dia do ciclo de seca, porque os primeiros têm maior quantidade de massa verde que os segundos, portanto perdem mais água por transpiração. No tratamento seco, a diferença foi menos importante $( \pm 3 \%)$ devido à adaptação à seca de todas as plantas.

A Figura 6 mostra os valores de TRA num ciclo de seca no estádio reprodutivo. O tratamento irrigado sempre mostrou menores valores de TRA que o seco,decorrido o mesmo tempo após a irrigação, tanto na avaliação feita no período vegetativo como no reprodutivo.

As retas do tratamento irrigado sempre foram mais inclinadas que as do seco, mormente no estádio reprodutivo, devido ao maior número de ciclos de seca neste.

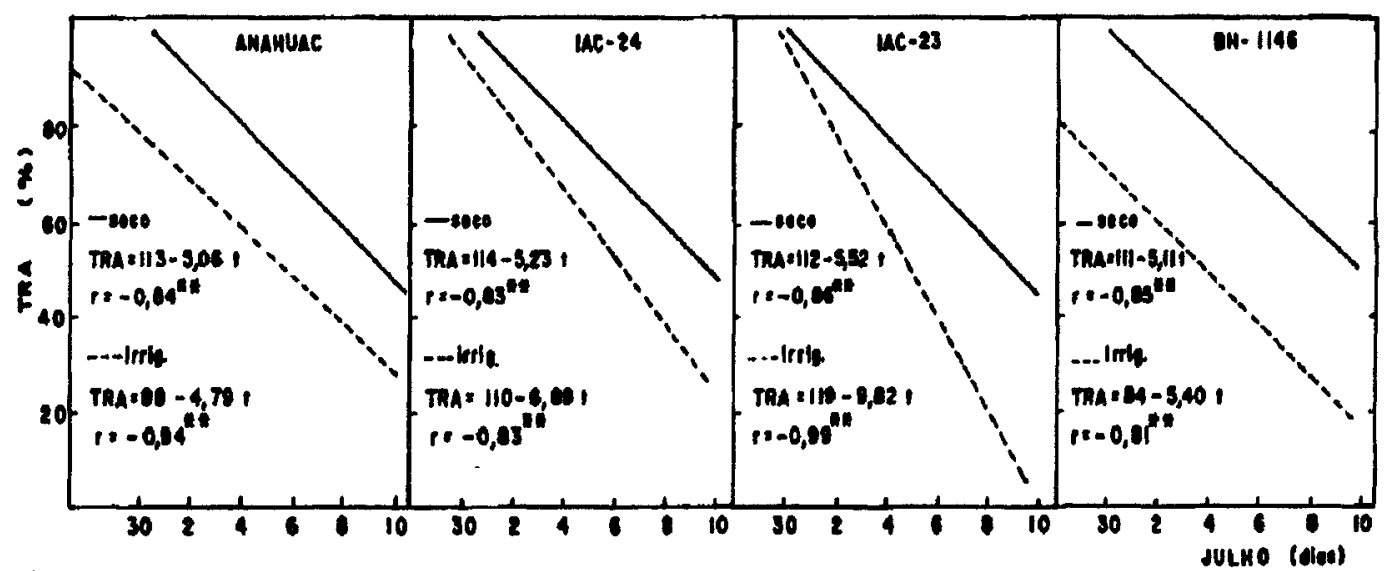

Figura 5 - Teor Relativo de água das folhas $x$ Tempo num ciclo de seca - Estádio vegetativo

Sci. agric., Piracicaba, 52(2):274-281, mai./ago. 1995 


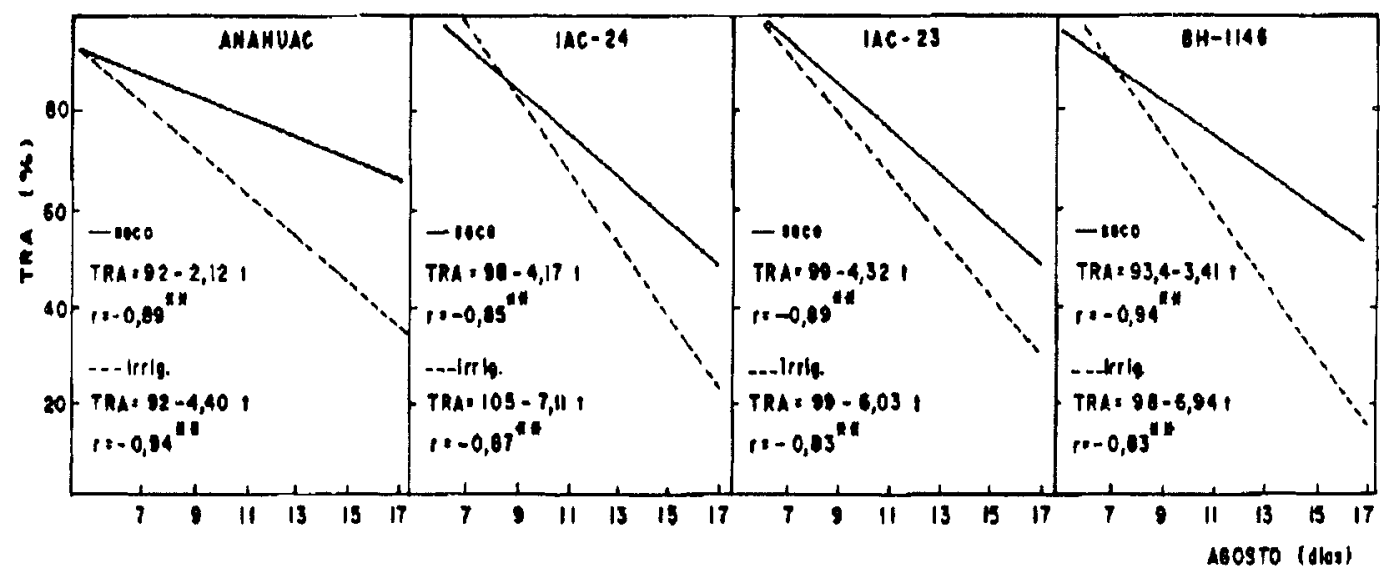

Figura 6 - Teor Relativo de água nas folhas $\mathrm{x}$ Tempo num ciclo de seca - Estádio reprodutivo; (ANAHUAC e IAC - 24 - Porte baixo; IAC - 23 e BH - 1146 - Porte alto) * $\mathrm{e}^{* *}$ - Significativos a 5 e a $1 \%$, respectivamente

\section{CONCLUSŌES}

- Os potenciais e os teores relativos de água nas folhas foram mais elevados nas plantas submetidas a ciclos de estresse hídrico $\mathrm{cm}$ relação às irrigadas constantemente sob os mesmos potenciais de água do solo;

- os potenciais de água das folhas, críticos do fechamento dos estômatos, foram mais baixos nas plantas submetidas a ciclos de seca que naquelas sempre irrigadas, mas não permitiram separar genótipos mais ou menos resistentes à seca;

- usando-se a resistência difusiva dos estômatos como avaliação de tolerância à seca em cultivares, verificou-se que o BH-1146, porte alto, se ressentiu mais rapidamente do deficit hidrico;

- decorridos alguns dias de um ciclo de seca, a diferença entre os potenciais de água do tratamento irrigado constantemente e do submetido a ciclos de seca mostrou sua viabilidade como método para separar cultivares tolerantes ou não à seca.

\section{AGRADECIMENTOS}

Ao Dr Carlos Eduardo O. Camargo pelas sugestões e fornecimento das sementes. Aos Srs. Vicente José de Vasconcelos e Gilberto Winckler pelos auxílios prestados.

\section{REFERÊNCIAS BIBLIOGRÁFICAS}

BLUM, A; GOZLAN, G.; MAYER, J. The manifestation of dehydratation avoidance in wheat breeding germplasm. Crop Science, Madison, v.21, p.494-499, 1981.
BRUCKENER, P.L.; FROHBERG, R.C. Stress tolerance and adaptation in spring wheat Crop Science, Madison. v 27, p.31-36, 1987.

EHRLER, W.L; NAKAYAMA, FS Water stress status in guayule as measured by relative leaf water content. Crop Science, Madison, v.24, p 61-66, 1984.

FELÍCIO, J.C.; CAMARGO, C.E.O.; FREITAS, J.G.; FERREIRA FILHO, A.W.P.; BARROS, B.C.; CAMARGO, M.B.P. Avaliação de genótipos de trigo para região do Vale do Paranapanema no quadriênio 1981-84 Bragantia, Campinas, v.45, p.257-278, 1986

GRAFIUS, J.E.; NELSON, W.L.; DIRKS, D.A. The heritability of yield in barley as measured by early generation bulked progeny. Agronomy Journal, Madison, v.44, p 253-257, 1965.

HAND, J.M.; YOUNG, E; VASCONCELOS, A.C. Leaf water potential, stomatal resistance, and photosynthetic response to water stress in peach "seedlings Plani Physiology, Ròckville, v.69, p.l051-1054, 1982.

HOFMANN, W.C.; O'NEIEL, M.K.; DOBRENZ, A.K Physiological responses to sorghum hybrids and parental lines to soil moisture soil. Agronomy Journal, Madison, v 76, p.223-228, 1984.

KLAR, A.E. A água nos sistema solo-planta-atmosfera. São Paulo, Nobel. 1988. 408p

KLAR, A.E.; DENADAI, I.A.M.; CATÃNEO, A. Resistência à seca de nove cultivares de trigo no Estado de São Paulo. In: CONGRESSO NACIONAL DE IRRIGAÇÃO E DRENAGEM, 8., Florianópolis, 1988. Anais... Florianópolis: Associação Brasileira de Irrigação e Drenagem, 1988. p.181-201. 
KLAR, A.E.; USBERTI, J.A.; HENDERSON, D.W. Differential responses of guinea grass populations to drought stress. Crop Science, Madison, v.18, p.853-857, 1978.

KLAR, A.E.; CATÂNEO, A; DENADAI, I.A.M.; SAAD, J.C.C.; PICARELLI, M. Medidas da adaptação de plantas de trigo à deficits hídricos. Científica, Jaboticabal, v.13, p.117-127, 1985.

LEVITT, J. Responses of plants to environmental stress. New York: Academic Press, 1972. 697p.

RODRIGUES, J.D.; KLAR, A.E.; PEDRAS, J.F.; RODRIGUES, S.D.; PINHO, S.Z. A influência de diferentes regimes de umidade do solo em gladíolos. ITranspiração, teor relativo de água e índice refratométrico. Phyton, Buenos Aires, v.39, p.57-76, 1980.
SAYED, 1.H. Response of wheat and triticale cultivars grown under field conditions to drought stress. Beiträge Tropischen Landwirtschaft und Veterinärmedizin, Leipzig, v.21, p.175-180, 1983.

THOMAS, J.C.; BROWN, K.W.; JORDAN, W.R. Stomatal response to leaf water potential as affected by preconditioning water stress in the field. Agronomy Journal, Madison, v.68, p.706-708, 1976.

Recebido para publicação em 01.07.94 Aceito para publicação em 04.05 .95 